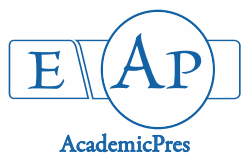

\title{
Bioremediation of Phenol by Mutated and Immobilized Aspergillus and Penicillium Species
}

\author{
Amany G. IBRAHIM ${ }^{1,2 *}$, Lujin S. AL-GHAMDI ${ }^{2}$ \\ ${ }^{1}$ Ain Shams University, Faculty of Women for Arts, Science, \& Education, Botany Department Cairo, \\ Egypt; amanygm@yahoo.com ("corresponding author);_Amany.gomaa@women.asu.edu.eg \\ ${ }^{2}$ Taif University, Faculty of Science, Biology Department, Saudi Arabia; thesilverwater21ss@hotmail.com
}

\begin{abstract}
Phenol and its chemical derivatives are essential for production of polycarbonates epoxies, bakelite, nylon, detergents, herbicides, and numerous pharmaceutical drugs. In order to increase the biodegradation of phenol by fungi, fungal strains (Aspergillus niger, Penicillium griseofulvum and Aspergillus terreus), were isolated from different contaminated sites in Saudi Arabia such as Jeddah Governate, the second industrial city of Jeddah, some garbage collection places, gas stations and Red Sea), then screened for phenol degradation. For the first time in Saudi Arabia, biodegradation of phenol by fungi is improved by mutation as well as immobilization of fungi above calcium alginate. The isolated fungal strains (Aspergillus niger, Penicillium griseofulvum and Aspergillus terreus), were mutated physically (UV) and chemically (Ethidium bromide), also immobilized in alginate beads and its phenol degradation efficiency was observed. The degradation was increased many fold after immobilization, but after mutation some mutants appeared highly degradation rate for the phenol such as Aspergillus niger, and Penicillium griseofulvum but Aspergillus terreus appeared highly degradation rate for the phenol only after exposure to UV for 5 and 10 mins only than the wild strains. In addition, phenol degradation was increased with increase the fungal disk size of the tested strains.
\end{abstract}

Keywords: biodegradation; enhancement; immobilization; mutation; phenol

\section{Introduction}

Phenol is a structure unit for the production of pharmaceuticals, such as, aspirin (Busca et al., 2008; Acosta et al., 2018). Phenol can be used with chloroform (a commonly-used mixture in molecular biology for DNA \& RNA purification from proteins), also used for cell disruption and lysis purpose (Sambrook and Russell, 2001).

It can be absorbed through the skin, inhalation and by swallowing (Germain et al., 2019). The typical main absorption way is the skin, through which phenol is resorbed rapidly; simultaneously causing burns on the area of skin (Rappoport, 2003).Contact with phenol may result in irritation of eye, conjunctional swelling, corneal whitening and finally blindness. The continuous exposure to phenol can induce renal damage (Germain et al., 2019). Other effects include fizzing from mouth, nose and subsequently headache. Chronic exposure may result in rashes, vomiting, weakness; lose in weight, pain in muscles and nervous (Downs and Wills, 2019). Due to muscle weakness, paralysis can be also being followed. It is also suspected that cancer and striation can also be caused. Phenol and its derivatives are poisonous and classified as dangerous materials (Zumriye and Gultac, 1999; ATSDR, 2007). Ingestion of phenol for a prolonged period of time causes mouth sore, diarrhea, excretion of dark urine and impaired vision at concentrations levels ranging between 10 and $240 \mathrm{mg} / \mathrm{L}$ (Álvarez-Torrellas et al., 2017).

Due to presently increasing concern of pollution and its effect, the pollution control methods are getting more attention and are equally more important because all the pollutants released in atmosphere are very harmful to human in form of some disease or disorder in the environment. From the list of many pollutants, one of the pollutants is phenol which is $11^{\text {th }}$ most toxic compound out of 126 toxic compounds given by environmental protection agency (EPA) (Saluja, 2015). Phenol released from industries in free form or in the form of phenol derivative is main problematic cause for pollution of soil and water (Saluja, 2015).

Phenol is degraded by so many microbes which utilizes phenol as the sole carbon source for their growth (Rudzanova et al., 2019). Several microbes both anaerobic

Received: 11 Oct 2019. Received in revised form: 13 Nov 2019. Accepted: 13 Dec 2019. Published online: 24 Dec 2019. 
and aerobic microorganisms degrading phenol are isolated and characterized (Nair et al., 2008), while microorganisms capable of aerobic phenol degradation were defined as early as 1908 (Van Schie and Young, 1998).

Along with bacteria, fungi are known for their multiplicity and notable ability in degrading phenolic compounds. Conflicting to bacteria, fungi can grow under ecologically stressed environments such as low nutrient availability, low water activity and at low $\mathrm{pH}$ values where bacterial growing might be inadequate (Saluja, 2015).

Cell immobilization has been well-defined as the physical confinement or localization of viable microbial cells to a certain defined region of space in such a way as to limit their free movement and exhibit hydrodynamic characteristic which differ from those of the surrounding environment while retaining their catalytic activities for repeated and continuous use (Freeman and Lilly, 1998; Covizzi et al., 2007; Amim et al., 2010; Mrudula and Shyam, 2012). Immobilization technique could increase the efficiency of the microbial cell viability and/or growth (Doran and Baily, 1986).

To increase and enhancement the efficiency of biological treatment of phenol, the present study focused on mutation chemically and physically and immobilization of fungal strains that were isolated previously (Ibrahim and ELGamdi, 2019), using Ca-alginate beads.

\section{Materials and Methods}

\section{Phenol determination}

For the determination of phenol content, the FolinCiocalteau phenol reagent was used. To the $0.1 \mathrm{ml}$ of supernatant liquid add $0.1 \mathrm{ml}$ of $2 \%$ of sodium carbonate $\mathrm{Na}_{2} \mathrm{CO} 3,0.1 \mathrm{ml}$ of Folin- Ciocalteau reagent and add $2 \mathrm{ml}$ of distilled water. Then it is kept aside for 60 minutes at 20 ${ }^{\circ} \mathrm{C}$. Then the absorbance was measured at $727 \mathrm{~nm}$ against distilled water and reagent blank (Leonard and Lindley, 1998). All samples are measured by the spectrophotometer, and then phenol concentration was determined. The bioremoval efficiency of the strains was then calculated according to the following formula:

\% Phenol Removal Efficiency $(\mathrm{PRE})=\left(\mathrm{C}_{\mathrm{i}}-\mathrm{C}_{\mathrm{f}} / \mathrm{C}_{\mathrm{i}}\right) \times 100$

Where $c_{i}$ is the initial concentration of phenol $(\mathrm{mg} / \mathrm{L})$ and $c_{f}$ is the final concentration of phenol

\section{Effect of different fungal disk size on the growth and degradation rate}

Experiments were performed in three of $250 \mathrm{ml}$ flask containing $100 \mathrm{ml}$ of mineral salt medium (MSM), containing liquid phenol as sole carbon and energy source after medium sterilization, fungal disk of 5 days old culture (A. niger, P. griseofulvum and A. terreus), with (2-5 and 7 $\mathrm{mm}$ ) was used as inoculum on the tested medium (Abd ElZaher $e$ al., 2011), then incubation of the flasks at $27 \pm 2$ ${ }^{\circ} \mathrm{C}$ for one week. After incubation, the determination of phenol content was measured by using Folin-Ciocalteau phenol reagent.

Effect of different concentration of phenol on the growth and degradation rate

Experiments were performed in three of $250 \mathrm{ml}$
Erlenmeyer flask containing $100 \mathrm{ml}$ of MSM, the medium containing phenol at concentration ranging $(0.01,0.05$, $0.08,0.1,0.2,0.5$ and $0.8 \mathrm{~g} / 100 \mathrm{ml})$, which were added by micro filter $(0.45 \mu \mathrm{m})$ after medium sterilization, as sole carbon and energy source then add fungal disk of 5 days old culture, with $7 \mathrm{~mm}$ diameter from fungal strains (Aspergillus niger, Penicillium griseofulvum and Aspergillus terreus), were used as inoculum on the tested medium (Abd El-Zaher $e t$ al., 2011), then incubation of the flasks at $27 \pm 2{ }^{\circ} \mathrm{C}$ for one week. After incubation, the determination of phenol content was measured by using Folin-Ciocalteau phenol reagent.

Increasing the biodegradation rate of phenol by different methods

\section{A-Physical mutation by $U V$}

For UV-mutagenesis, spores obtained from 5-day old cultures of $A$. niger, $P$. griseofulvum and $A$. terreus were suspended in sterile distilled water and exposed to UV-light $(254 \mathrm{~nm})$ from Philips TUV-30 W lamp source at a distance of $25 \mathrm{~cm}$ for $5,10,15,30$ and 60 minutes. The treated conidia were put in dark for one hour, and transferred to dishes with potato dextrose agar (PDA) supplemented with liquid phenol (El-Bondkly and Keera, 2007), and one $\mathrm{ml}$ of the the treated conidia transferred into 250 flasks, each flask contains $100 \mathrm{ml}$ mineral medium (MSM). The medium was then supplemented with liquid phenol as sole carbon and energy source (Jacob and Sohail, 2010). All samples are incubated in incubators at $27 \pm 2{ }^{\circ} \mathrm{C}$ for 1 week. For the determination of phenol content, the Folin-Ciocalteau phenol reagent was used.

\section{$B$-Chemical mutation by ethidium bromide (EtBr)}

$A$. niger, $P$. griseofulvum and $A$. terreus were grown as previously described and pelleted by centrifugation at 5000 rpm for $10 \mathrm{~min}$. The resulted pellets were suspended in solution of $3 \% \mathrm{NaCl}(\mathrm{w} / \mathrm{v})$. Subsequently, various ethidium bromide $(\mathrm{EtBr})$ concentration $(50,100,150$ and 200 $\mu \mathrm{g} / \mathrm{ml})$, were added to the fungal cells. After the examined exposure period (24 hours), cells were pelleted again, washed by phosphate buffer saline at $\mathrm{pH} 6.8$, and inoculated into mineral salt agar containing phenol, then incubated for 2-7 days at $27 \pm 2^{\circ} \mathrm{C}$. The survived cells were then selected and cultivated on PDA broth (Katrcolul et al., 2003). The activity of fungal strains for degradation was monitored by measuring phenol content by using the Folin-Ciocalteau phenol reagent.

\section{C-Immobilization of the fungal strains in alginate beads}

Spore suspension of our strains from potato dextrose agar plates was suspended in a previously autoclaved solution of sodium alginate to a final concentration of 40 $\mathrm{g} / \mathrm{L}$ and $100 \mathrm{~mL} / \mathrm{L}$ biomass. Beads without fungi, served as the controls. The alginate-fungi mixture was added drop wise with a sterile syringe $(20 \mathrm{~mL})$ fitted with a wide pore needle $(1 \mathrm{~mm}$ diameter) from a height of about $20 \mathrm{~cm}$ into an autoclaved solution of calcium chloride $(30 \mathrm{~g} / \mathrm{L}$, adjusted to $\mathrm{pH}=7.0$ ), where beads formed immediately. The beads were left in this hardening solution overnight at $4^{\circ} \mathrm{C}$ before being harvested by filtration and washed thoroughly with fresh culture medium to remove the un-entrapped free hyphae under aseptic conditions (Mohanty and Jena, 2016). 
412

Storage stability and reusability of immobilized cells

Free and immobilized cells were tested for phenol degradation. Cells were grown at $27 \pm 2{ }^{\circ} \mathrm{C}$ for one week in MSM $(\mathrm{pH}=7)$, containing phenol as sole carbon source, and the phenol degradation rate was detected. The immobilized cells were incubated in MSM for 1 week (Mohanty and Jena, 2016). For the determination of phenol content, the Folin-Ciocalteau phenol reagent was used.

\section{Results}

Effect of different size of fungal disk on the growth and degradation rate

It was noticed that phenol degradation increased with the increasing the size of fungal disk for all tested isolates that appeared with reduction in absorbance as shown in Fig. 1.

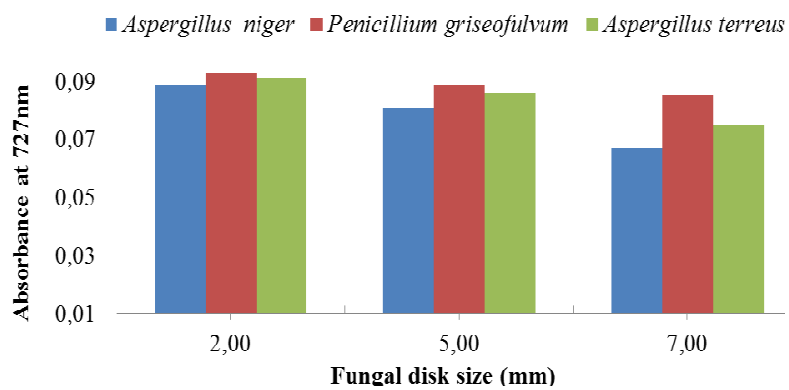

Fig. 1. Effect of fungal disk size on the degradation rate of phenol measured as absorbance at $727 \mathrm{~nm}$
Effect of different concentration of phenol on the growth and degradation rate

Data presented in Fig. 2 and Table 1, showed that the degradation rate of phenol was decrease with increasing the concentration of phenol $(0.01,0.05,0.08,0.1,0.2,0.5$ and $0.8 \mathrm{~g} / 100 \mathrm{ml}$ ) for fungal strains, the best degradations appear as reduction in absorbance at $727 \mathrm{~nm}$ as mentioned before in the materials and methods by using FolinCiocalteau reagent.

Increasing the biodegradation rate of phenol by different methods

\section{A-Physical mutation by $U V$}

The results were as follows: increases the growth of $A$. niger as the time of exposure to UV increases, decreases the growth of $P$. griseofulvum and $A$. terreus as the time of exposure to UV increases as shown in Fig. 3.

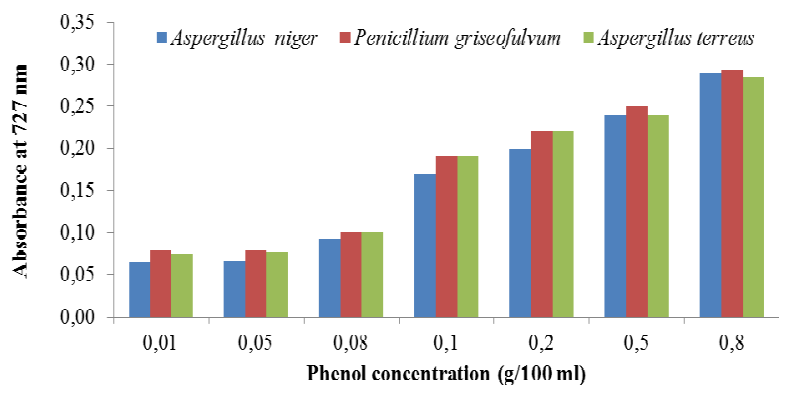

Fig. 2. Effect of different concentration of phenol on the degradation rate of fungal strains measured as absorbance at $727 \mathrm{~nm}$

Table 1. Degradation rate (\%) of the fungal strains with different concentration of phenol using spectrophotometer at $727 \mathrm{~nm}$

\begin{tabular}{cccc}
\hline \multirow{2}{*}{ Phenol concentration $(\mathrm{g} / 100 \mathrm{ml})$} & \multicolumn{2}{c}{ Degradation rate of phenol (\%) } \\
\cline { 2 - 4 } & Aspergillus niger & Penicillium griseofulvum & 17 \\
0.01 & 28 & 13.3 & 13.1 \\
0.05 & 27 & 11 & 11 \\
0.1 & 16 & 4.4 & 6 \\
0.2 & 15 & 4.3 & 4 \\
0.5 & 13 & 0.4 & 3.9 \\
0.8 & 4 & 0.3 & 1.5 \\
\hline
\end{tabular}

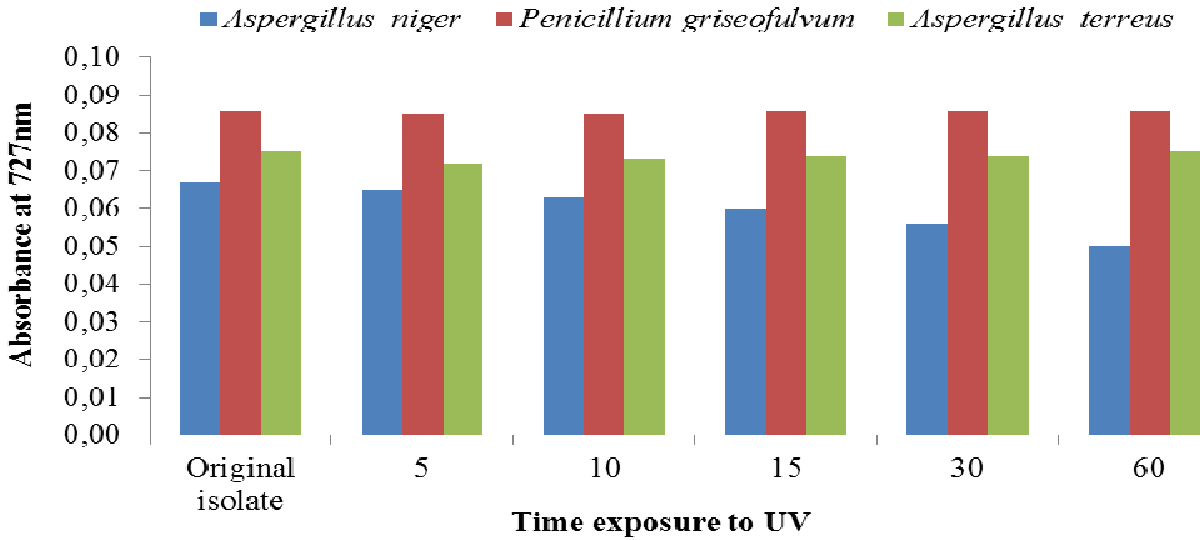

Fig. 3. Effect of exposure of fungal strains to different time of UV (5, 10, 15, 30 and $60 \mathrm{~min}$.) on phenol degradation rate using spectrophotometer which appeared as reduction in absorbance at $727 \mathrm{~nm}$ 
$B$ - Chemical mutation by ethidium bromide (EtBr)

As shown in Fig. 4, the results were as follows, increases the growth of $A$. niger, $P$. griseofulvum as the time of exposure to $\mathrm{EtBr}$ increases, and decreases the growth of $A$. terreus as the time of exposure to EtBr increases.

C-Immobilization of the fungal strains in alginate beads

Encapsulation of $A$. niger, $P$. griseofulvum and $A$. terreus into $\mathrm{Ca}$ - alginate beads were performed and the results are shown in Table 2 and Fig .5, which revealed that the degradation rate of phenol was increased by immobilized cells more than the free cells that appeared with reduction in absorbance. Controls (Ca-alginate beads without fungal cells in MSM medium containing phenol), demonstrating that phenol cannot adsorb by these beads and therefore no degradation was occurred.

\section{Discussion}

Phenolic compounds are public waste product in the production of industrial and agricultural products. Particularly, phenolic compounds are found in wastewaters from coal processing plants, oil refineries, pulp and paper manufacturing plants, resins and coke manufacturing, steel industries, pharmaceutical industries, plastic and varnish industries, textile units, pesticide plants, tannery, smelting and related metallurgical operations (Marrot et al., 2006; Bodalo et al., 2008; Jayachandran and Kunhi, 2008).

Phenol may present in air, sea water or surface water, soil or sewage. Now, the associated problem due to phenol is that when it is persist in waste water, even in low concentrations, it can be poisonous to some aquatic species (Rittmann and McCarty, 2001).

Table 2. Effect of free and immobilized fungal strains on phenol degradation rate measured as absorbance at $727 \mathrm{~nm}$ by spectrophotometer

\begin{tabular}{ccc}
\hline Fungal strains & & Degradation rate of phenol (\%) \\
\cline { 2 - 4 } & Free cells & Immobilized cells \\
\hline Aspergillus niger & 29 & 40 \\
Penicillium griseofulvum & 12 & 21 \\
Aspergillus terreus & 17 & 31 \\
\hline
\end{tabular}

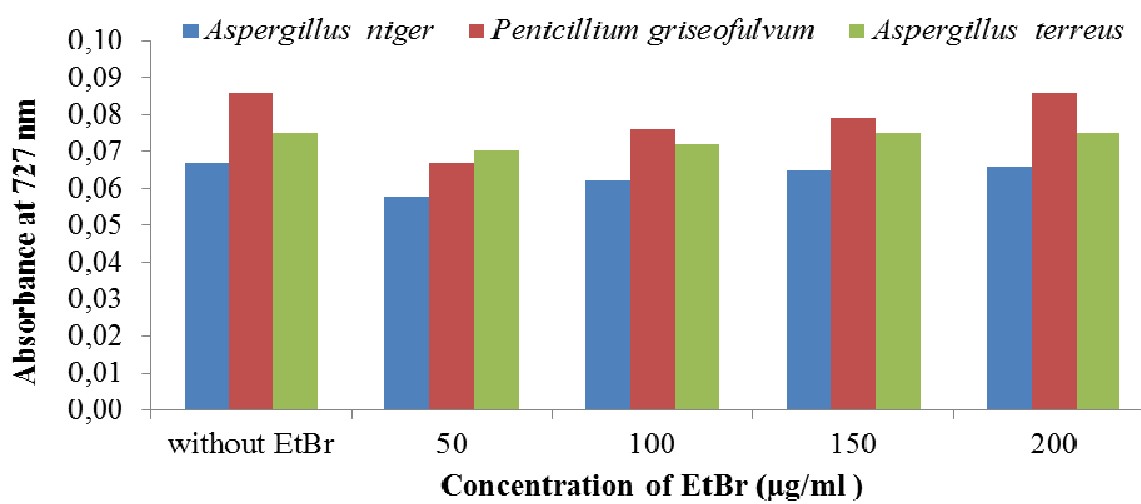

Fig. 4. Effect of exposure of fungal strains to different concentration of $\mathrm{EtBr}(5,100,150$ and $200 \mu \mathrm{g} / \mathrm{ml})$ on phenol degradation rate using spectrophotometer which appeared as reduction in absorbance at $727 \mathrm{~nm}$

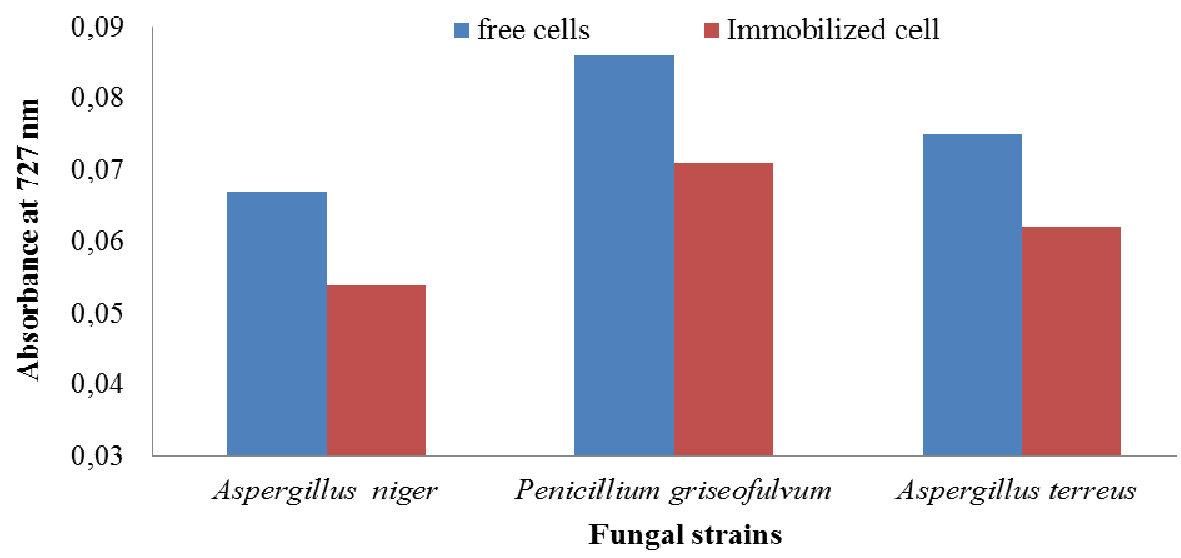

Fig. 5. Effect of free and immobilized selected fungal strains on phenol degradation rate using spectrophotometer which appeared as reduction in absorbance at $727 \mathrm{~nm}$ 
414

Fungi are capable of metabolizing phenol by enzymatic mechanisms (Agarry et al., 2008). Biodegradation of phenol by fungi is influenced by number of factors; the substrate concentration is an important factor in the phenol biodegradation, as phenol itself, is well known to inhibit microbial growth, especially at greater concentrations. This phenomenon is commonly known as substrate inhibition. High concentration of a phenol can be preventing the growth of microorganisms, and the concentration at which inhibition occurs varies from compound to another (Alexander, 1985).

Adjei and Ohta (2000) reported that phenol was completely inhibitory for cyanide utilization by the bacteria Burkholderia cepacia strain C-3. (Wei et al., 2008), studied the influence of substrate concentration on the biodegradation efficiency by varying initial phenol concentration from $100 \mathrm{mg}$ to $1000 \mathrm{mg} / \mathrm{l}$.

In the present study, high concentration of a phenol can be prevent the the growth of fungal strains, that the degradation rate of phenol was decrease with increasing the concentration of phenol $(0.01,0.05,0.08,0.1,0.2,0.5$ and $0.8 \mathrm{~g} / 100 \mathrm{ml}$ ). Similar results were obtained by (Supriya and Neeha, 2014), they showed that maximum phenolic degradation by $A$. niger was observed at $300 \mathrm{mg} / \mathrm{l}$, this due to the fact that the phenol degrading enzymes activity is optimum at this concentration.

Phenol removal at lower concentrations is attributed to the presence of more available sites on the adsorbent (fungi biomass) than the number of phenol ions which are available in solution. The bio-treatment in our study was proportional to the concentration. This agrees with the results of (Moyo et al., 2012), who showed that the yeast Saccharomyces cerevisiae used phenol as the sole energy and carbon source and tolerated up to $120 \mathrm{mg} / \mathrm{L}$ phenol.

Results obtained in this study revealed that phenol degradation increased with the increasing the size of fungal disk for all tested strains $(2,5$ and $7 \mathrm{~mm}$ ). An adequate number of inoculums were necessary to minimize the period of the lag phase, increase the degradation rate, and prompt the exponential growth phase after seeding. Similar results were obtained by (Balamurugan et al., 2012), who showed that sufficient quantity of inoculums of $A$. fumigatus ensures rapid proliferation and biomass synthesis in cultivation. Phenol degradation at an initial concentration of $400 \mathrm{mg} / \mathrm{l}$ was achieved at an inoculum concentration of $313 \%(\mathrm{v} / \mathrm{v})$ at $\mathrm{pH} 7.5$ and $30{ }^{\circ} \mathrm{C}$. At low inoculums concentrations (3-5\%), microbial growth had a prolonged lag phase when the inoculums concentration was increased to $7-10 \%(\mathrm{v} / \mathrm{v})$, the lag phase was largely eliminated.

Physical (UV-light) and chemical (EtBr) mutagens proved to be powerful in inducing a wide range of genetic variability. The results in this study proved that $P$. griseofulvum and $A$. terreus were sensitive to UV radiation. Lethality was increased with radiation time and reached 95\% at 15 minutes, after which it become constant. Thus, 5 and 10 minutes appeared to be an appropriate radiation time for further studies. But the mutant strain $A$. niger show a higher phenol-degrading efficiency increased with radiation time, these results showed that the mutant strain $A$. niger, has more tolerant than the wild strain until after 60 minutes, and the mutant strains $P$. griseofulvum and $A$. terreus has more tolerant than the wild strain until after 5 and 10 minutes only. The enhanced phenol-degrading efficiency of mutant strains may result from the increase in the activity of the related enzymes.

Many papers reported that UV mutagenesis has a positive effect on increasing the biodegradation ability of strains (Chen et al., 2011; Joshi et al., 2016). Yet, another study showed that UV mutagenesis had no influence on degradation efficiency (Sekar et al., 2009). Similar results were obtained by (Zhen et al., 2015), who indicated that the mutant strain Pseudochrobactrum sp. XF1 has more tolerant over a wide range of $\mathrm{pH}$ values than the wild strain (ELBondkly and Keera, 2007), who observed that UVirradiation and $(\mathrm{EtBr})$ were applied in different doses for inducing mutations in the $P$. roquefortii. Results show the gradual increase of the lethality which was associated with the increase of the mutagen dosage. On the other hand, the survival percentages decreased by increasing $(\mathrm{EtBr})$ doses.

Immobilization technique could increase the efficiency of the microbial cell viability and/or growth (Doran and Baily, 1986). Entrapment of fungal cells using insoluble calcium alginate is a rapid method, non-toxic, inexpensive and versatile. More than $80 \%$ of cell immobilization process is still carried out using alginate (Thu et al., 1996).

Immobilization could increase the efficiency of the microbial cell viability, growth and some properties (Doran and Baily, 1986). Also (Wiesel et al., 1993), reported that immobilization is considered to promote better survival and activity of some microorganisms. These observations confirmed our results on phenol degradation with immobilized and free fungal cells, as well as control (Caalginate beads without fungi). Phenol cannot adsorb by control (beads without fungi), while the immobilized cells showed higher degradation rate as compared with free cells.

\section{Conclusions}

It can be concluded that phenol is so widely found and used in everyday activities; some factors that affect the degradation rate of phenol were studied in this work and revealed that, phenol degradation increased with the increase the size of fungal disks of the tested cultures. Also, phenol degradation increased as the incubation period increased. UV irradiation showed that the growth and degradation increases as the time of exposure to UV increases for $A$. niger and the growth and degradation decreases as the time of exposure to UV increases for $P$. griseofulvum and $A$. terreus. Also phenol degradation increased with immobilization of fungal strains.

\section{Conflict of Interest}

The authors declare that there are no conflicts of interest related to this article.

\section{References}

Abd El-Zaher F, Mahmoud G, Aly M (2011). Effect of different concentrations of phenol on the growth of some fungi isolated from contaminated soil. African Journal of Biotechnology 10(8):1384-1392. 
Acosta CA, López PCE, Paniagua G, Garcinuño RM, Fernández HP (2018). Evaluation of total phenol pollution in water of San Martin Canal from Santiago del Estero, Argentina. Environmental Pollution 236:265-272.

Adjei MD, Ohta Y (2000). Factors affecting the biodegradation of cyanide by Burkholderia 6 epacian strain C-3. Journal of Bioscience and Bioengineering 89:274-277.

Agarry SE, Durojaiye AO, Solomon BO (2008). Microbial degradation of phenols: a review. International Journal of Environment and Pollution 32:12-28.

Alexander M (1985). Biodegradation of organic chemicals. Environmental Science and Technology 18:106-111.

Álvarez-Torrellas S, Martin-Martinez M, Gomes HT, Ovejero G, Garcíaa J (2017). Enhancement of p-nitrophenol adsorption capacity through N2-thermal-based treatment of activated carbons. Applied Surface Science 414:424434.

Amim Jr J, Petri DFS, Maia FCB, Miranda PB (2010). Ultrathin cellulose ester films: preparation, characterization and protein immobilization. QuímicaNova33(10):20642069.

ATSDR (Agency for Toxic Substances and Disease Registry) ( 2007). Notice of the revised priority list of hazardous substances that will be the subject of toxicological profiles.

Balamurugan AN,Loganathan G, Bellin MD, Wilhelm JJ,Harmon J, Anazawa T,... Hering BJ (2012). A new enzyme mixture to increase the yield and transplant rate of autologous and allogeneic human islet products. Transplantation 93(7):693.

Bodalo A, Gomez JL, Gomez M, Leon G, Hidalgo AM, Ruiz MA (2008). Phenol removal from water by hybrid processes: study of the membrane process step. Desalination 223(1-3):323-329.

Busca G, Berardinelli S, Resini C, Arrighi L (2008). Technologies for the removal of phenol from fluid streams: A short review of recent developments. Journal of Hazardous Material 160:265-288.

Chen J, Yang QY, Huang TP, Zhang YK, Ding RF (2011). Enhanced bioremediation of soil contaminated with viscous oil through microbial consortium construction and ultraviolet mutation. World Journal of Microbiology and Biotechnology 27:1381-1389.

Covizzi LG, Giese EC, Gomes E, Dekker RFH, Silva R (2007). Immobilization of microbial cells and their biotechnological applications. Semina: Ciências Exatas Tecnológicas 28:143-160.

Doran PMA, Baily JE (1986). Effect of immobilization on growth, fermentation properties, and macromolecular composition of Sacharomyces cervisiae attached to gelatin. Biotechnology and Bioengineering 28:73-87.

Downs JW, Wills BK (2019). Phenol toxicity Book. Stat Pearls Publishing LLC.

EL-Bondkly A, Keera A (2007). UV- and EMS- induced mutations affecting synthesis of alkaloids and lipase in Penicillium roquefortii. Arabian Journal of Chemistry 10(2):241-248.

Freeman A, Lilly MD (1998). Effect of processing parameters on the feasibility and operational stability of immobilized viable microbial cells. Enzyme and Microbial Technology 23:335-345.

Germain T, Lynda E, Tchirioua E(2019). Adsorption of phenol on carbon based on cactus and banana peel. Australian Journal of Basic and
Applied Sciences 13(1):6470.

Ibrahim GA, EL-Gamdi SL (2019). Characterization of fungi that able to degrade phenol from different contaminated areas in Saudi Arabia. Journal of Biological Sciences 19:210-217.

Jacob HJ, Sohail A (2010). Isolation of two fungal strains capable of phenol biodegradation. Journal of Biological Sciences 10:162-165.

Jayachandran VP, Kunhi AAM (2008). Degradation of 3-chlorobenzoate and phenol singly and in mixture by a mixed culture of two orthopathway- following Pseudomonas strains. Journal of Industrial Microbiology and Biotechnology 5:120-122.

Joshi DR, Zhang Y, Tian Z, Gao Y, Yang M (2016). Performance and microbial community composition in a long-term sequential anaerobicaerobic bioreactor operation treating coking wastewater. Applied Microbiology and Biotechnology 100(18):8191-8202.

Katrcolul H, Aslm B, Nur ZY, Mercan N, Beyatl Y (2003). Production of poly-hydroxybutyrate (PHB) and differentiation of putative Bacillus mutant strains by SDS-PAGE of total cell protein. African Journal of Biotechnology 2:147-149.

Leonard D, Lindley ND (1998). Carbon and energy flux constraints in continuous cultures of Alcaligenes eutrophus grown on phenol. Microbiology 144:241-248.

Marrot B, Barrios-Martinez A, Moulin P, Roche N (2006). Biodegradation of high phenol concentration by activated sludge in an immersed membrane bioreactor. Biochemical Engineering Journal 30:174183.

Mohanty SS, Jena HM (2016). Biodegradation of phenol by free and immobilized cells of a novel Pseudomonas sp. NBM11. Brazilian Journal ofChemical Engineering 34(1):75-84.

Moyo M, Mutare E, Chigondo F, Nyamunda B (2012). Removal of phenol from aqueous solution by adsorption on yeast, Saccharomyces cerevisiae. International Journal of Research and Reviews in Applied Sciences 11:486-494.

Mrudula S, Shyam N (2012). Immobilization of Bacillus megaterium MTCC 2444 by Ca-alginate entrapment method for enhanced alkaline protease production. Brazilian Archives of Biology and Technology 55:135-144.

Nair CI, Jayachandran K, Shashidhar S (2008). Biodegradation of phenol. African Journal of Biotechnology 7(25):4951-4958.

Rappoport ZVI (2003). The chemistry of phenols. Edited by Zvi. Rappoport. The Hebrew University,Jerusalem Ltd.

Rittmann BE, McCarty PL (2001). Environmental biotechnology: principles and applications. McGraw-Hill Education. New York.

Rudzanova D, Luptáková A, Macingova E (2019). The possibilities of using sulphate-reducing bacteria for phenol degradation. Physicochemical Problems of Mineral Processing 55(5):1148-1155.

Saluja M (2015). Isolation and characterization of phenol degrading organisms from soil sample containing traces of crude oil. Rourkela769008http://ethesis.nitrkl.ac.in/7950/1/2015_Isolation_Saluja.pdf.

Sambrook J, Russell D (2001). Molecular cloning: a laboratory manual. 3rd. ed. Cold Spring Harbor Laboratory, New York.

Sekar S, Sivaprakasam S, Mahadevan S (2009). Investigations on ultraviolet light and nitrous acid induced mutations of halotolerant bacterial strains for the treatment of tannery soak liquor. International Biodeterioration and Biodegradation 63:176-181. 
416

Supriya CH,Neeha D (2014). Biodegradation of phenol by Aspergillusniger. Journal of Pharmacy 4(7):11-17.

Thu B, Smidsrod O, Skjak-Break G (1996). Progress in biotechnology, immobilized cells: basics and application. Biotechnology Annual Review 19-31.

Van Schie PM, Young LY (1998). Isolation and characterization of phenoldegrading denitrifying bacteria. Applied and Environmental Microbiology 64(7):2432-2438.

Wei G, Yu J,Zhu Y, Chen W, WangL (2008). Characterization of phenol degradation by Rhizobium sp. CCNWTB 701 isolated from Astragalus chrysopteru in mining tailing region. Journal of Hazardous Materials 151:111-117.

Wiesel I, Wubker SM, Rehm HJ (1993). Degradation of polycyclic aromatic hydrocarbons by an immobilized mixed bacterial culture. Applied Microbiology and Biotechnology 39:110-116.

Zhen M, Chenyang Y, Lingling X (2015). Enhancement of phenol biodegradation by Psendochrobactrum sp. through ultraviolet-Induced mutation. International Journal of Molecular Sciences 16:7320-7333.

Zumriye A, Gultac B (1999). Determination of the effective diffusion coefficient of phenol in calcium alginate immobilized Pseudomonas putida. Enzyme and Microbial Technology 25:344348. 